\title{
Towards a synergy between project and supply chain management
}

\author{
Sanjay Sharma*
}

National Institute of Industrial Engineering (NITIE), Vihar Lake, Mumbai-400087, India

\begin{tabular}{|c|c|}
\hline A R T I C L E I N F O & A B S T R A C T \\
\hline $\begin{array}{l}\text { Article history: } \\
\text { Received 10 March } 2012 \\
\text { Accepted May } 242012 \\
\text { Available online } \\
25 \text { May } 2012 \\
\text { Keywords: } \\
\text { Project Management } \\
\text { Supply chain } \\
\text { Housing construction } \\
\text { Categorization of the construction } \\
\text { product, and logistics }\end{array}$ & $\begin{array}{l}\text { Construction projects are conventionally analyzed considering factors such as cost and } \\
\text { completion time. The present paper focuses on the projects particularly dealing with the house or } \\
\text { building. The paper aims at an objective of introducing a synergy between project and supply } \\
\text { chain management. After a brief relevant literature review, major construction activities have } \\
\text { been discussed and the associated synergy between project management and supply chain } \\
\text { concepts has been explained. Applications of the supply chain concepts such as forward and } \\
\text { reverse logistics along with the customer order decoupling point in the context of construction } \\
\text { management are discussed as a result of the proposed development. For this purpose, a } \\
\text { categorization of construction product is developed on the basis of land and building } \\
\text { characteristics and it is the major contribution of the present paper. This is also expected to be } \\
\text { useful for estimating lead time and availability of the product in the context of relevant supply } \\
\text { chain, and an associated managerial implication. }\end{array}$ \\
\hline
\end{tabular}

\section{Introduction}

Uncertainties in demand and supply along with other factors have led to higher risks in the supply chain. The ability to match supply more closely with demand may be called agility and the key to agility is speed (Christopher \& Towill 2002). Synchronous supply requires transparency of demand and pipeline inventory in as close to real time as possible (Christopher \& Lee 2004). The following factors are critical to succeed (Giunipero \& Pearcy 2000) and even to survive in today's competitive arena:

(i) Negotiation skills

(ii) Interpersonal communication

(iii) Ability to work in teams

These are also the skills needed to support the integration of supply chain. Supply professionals should rely (Giunipero and Eltantawy 2004) on:

* Corresponding author.

E-mail: s_nsit@rediffmail.com (S. Sharma)

(c) 2012 Growing Science Ltd. All rights reserved.

doi: 10.5267/j.ijiec.2012.05.002 
(i) Early supplier involvement

(ii) Share and assess supplier risk management plans

(iii) Implement automatic integration with supplier operations

(iv) Increase and strengthen the flow of communication with the supplier

Supply chain concepts have generally been applied to products, such as concurrent engineering or product design (Fixson 2005). Supply chain process variability may include the internal factors as well as the inconsistencies in flows into and out of the firms (Germain et al. 2008). The contribution of this paper is to explore the synergy among the supply chain, the product, and the project management particularly the construction of houses. Reverse logistics is a specific branch of supply chain applied to the End Of Life (EOL) products. Many problems regarding the collection of EOL products lie within its operational aspect (Hanafi et al., 2008). Key concepts of the forward supply chain design may be useful for the development of reverse supply chain strategies (Blackburn et al., 2004). In the recovery process, returned products may be converted to different forms such as module, part, and material (Wikner \& Tang 2008). Postponement can act as a unifying concept for the forward and the reverse supply chain. The decisions made under certain consumer demands and the decisions made under uncertain demands (Wikner \& Rudberg, 2005a) are separated by the customer order decoupling point (CODP). Demand driven engineering adaptations have also been included (Wikner \& Rudberg, 2005b). Application of the forward and reverse supply chain along with the CODP is unconventional in the context of construction management. The present paper focuses on these aspects.

Now a brief literature review would be relevant concerning the construction business as a supply chain. The building or house is finally a product to be handed over to the customer. However taking a process view, there are certain key phases. Some of the important phases (Edum-Fotwe et al., 2001) are as follows:

(a) Effective demand by client

(b) Conceptual including design

(c) Construction including procurement

(d) Operation and maintenance of the construction facility

(e) De-commission/ demolition/ abandonment.

The process begins with a client requiring a building or house. The construction business may involve a large amount of information exchange process. As it is happening in other industries, the competition in the next decade is expected to be among different supply chains and not among individual companies in the construction business. In order to address the competition, the organizations have greater reliance on outsourcing (Hendry, 1995). The skills needed to operate the construction supply network have been examined (Briscoe et al., 2001). At the strategic level, the focus is on moving the whole organization towards achieving certain vision in spite of the presence of external pressures (Aritua et al., 2009). Analysis supports the suggestion that the construction industry operates in a multi-project environment (Chinyio et al., 1998). Integration of projects and strategic planning becomes necessary for considering both internal and external environments (Pellegrinelli, 2002; Morris et al., 2006). Competitive tendering-based strategies emphasize short-term value, while long-term value is emphasized in close relationship (Ahola, 2008).

As it is discussed before, concerning the objective of this paper, the next sections deal with certain related aspects. These aspects aim towards synergistic nature of supply chain and project management, in particular the construction of houses or buildings. 
In order to create this synergy, it is necessary to categorize the construction product in the context of the supply chain and this is one of the main research/ practice objectives. For achieving this objective, the following methodology is adopted:

(i) A brief study of the sequential activities in the house or building construction is made.

(ii) After exploring the price and quality parameters, an appropriate categorization is proposed. This is expected to be helpful in the further analysis of the research problem.

(iii) On the basis of lead time and availability, the proposed categorization is further analyzed in the context of customer order decoupling point (CODP) determination.

The present paper is organized in five sections including the introduction, i.e., the section 1 . Section 2 discusses the construction activities. On the basis of factors such as price and quality, various combinations for the land and building are generated. In addition to the price and quality, the supply chains may also compete on the factors such as availability of the products/ services and the lead time. Therefore the lead time and availability are the relevant issues for section 3. Since the housing projects are different in comparison with the general industrial products, section 4 presents this briefly in the context of reverse logistics. Finally the section 5 concludes this paper.

\section{Construction activities}

Typical activities in the construction are shown in Fig.1.

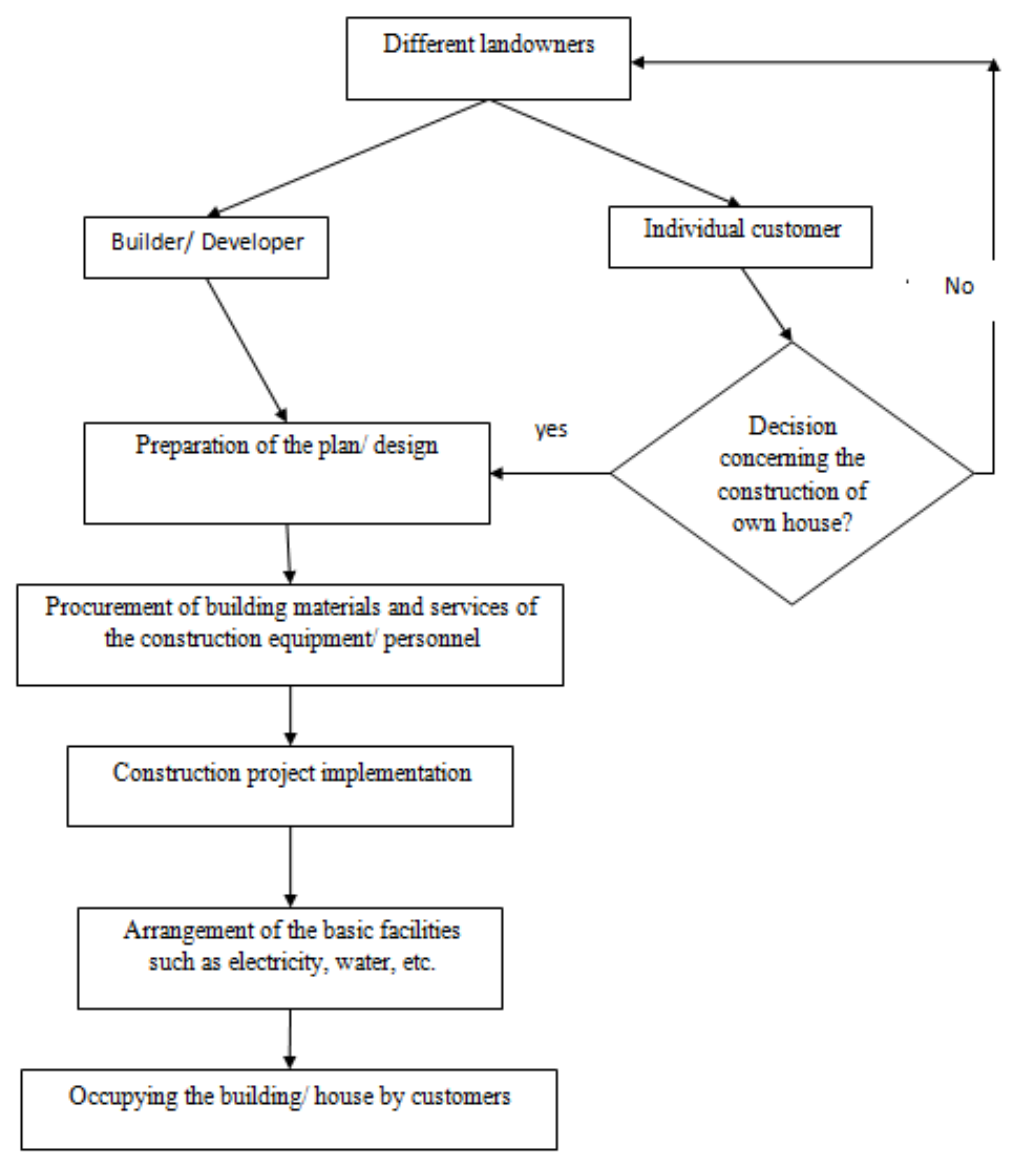

Fig.1: Typical activities in the housing construction

A land owner sells certain area for further use to the builder or developer. This may also be procured by an individual customer. Then different sequential activities are performed until the house or building is occupied by the intended customer(s). A progressive company involved in the project management 
can usually benefit from an appropriate analysis of these sequential activities. The objective of the present paper is to introduce a synergy between the project and supply chain management. Therefore, it is reasonable to discuss certain factors on which the general supply chains usually compete and then develop these factors in the precise context of construction management. Supply chains usually compete on the factors such as:

(i) Price

(ii) Quality (iii) Availability of the products/ services

(iv) Lead time

In the present context, the price and quality may be analyzed at two levels. Consider the interface of the land owners (potential sellers of the space) and builder/ developer, i.e., the two players in the supply chain. Land owners may be the government or private. Quality of the land (without any construction) may be judged from the analysis of the criteria such as the proximity of various facilities for a good life. Price of a piece of land may be dynamic depending on the supply-demand scenario. However for certain planning period, it can be categorized as 'low' or 'high'. A company involved in the project management activities can analyze it on the basis of specific location. For example, the perception of 'high' price at a location may also be treated as the 'low' price at another location. It is possible to develop suitable measurement scale. However it would be location specific. These two categories ('low' or 'high') are applicable for the quality level also. The conceptual diagram is shown in Fig.2. Apart from the land (without construction), the building/ house (i.e., the construction/ building materials and services) may also have such price-quality combinations.

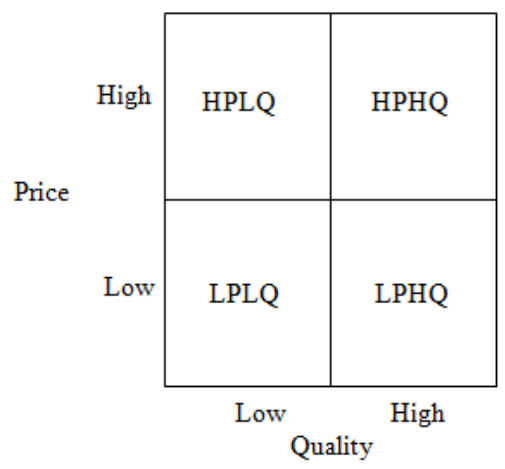

Fig. 2. Land/ building characteristics

With respect to the building characteristics, the quality characteristic may refer to:

(i) Building material

(iii) Various facilities provided in the design of the building

(iv) Implementation of the project in the context of channel activities.

Quality characteristic has been discussed before, considering:

(i) Quality of the land (without any building construction)

(ii) Quality with respect to the building characteristics.

Since the quality is a relative term. It should be perceived by the company involved in project management activities in the context of the specific customer group. For example, the perception of 'high' quality for a customer group may be treated as the 'low' quality for another customer group. A customer group specific measurement scale can conveniently be developed for categorization of the 
quality characteristic. The following combinations in the context of building characteristics may take place:

(i) Low Price-Low Quality (LPLQ)

(ii) Low Price-High Quality (LPHQ) (iii) High Price-High Quality (HPHQ)

(iv) High Price-Low Quality (HPLQ)

Out of these four possibilities, LPHQ and HPLQ seem unusual. However depending on the location and environment, even a low overall quality building may finally have high price. This may be due to the lack of supply chain orientation, inefficiencies in the procurement/ execution of goods/ services. At the same time, if the location of the building is nearer to the source of high quality material/ personnel/ equipment, LPHQ may be a possibility, though rare one. The remaining two combinations are LPLQ and HPHQ. It is needless to say that these occur usually in the real world for obvious reasons. It seems reasonable to consider these two building combinations for further development though it is possible to include that remain. Land characteristics also include price and quality. Low quality may refer to, for example, rural location, for want of the proximity to several facilities. All the four combinations, i.e., LPLQ, LPHQ, HPHQ, and HPLQ are retained because these may easily be observed in practice. The selected combinations for land and building are shown in Table 1. Prefix of ' $\mathrm{L}$ ' and ' $\mathrm{B}$ ' is used for distinction between the land and building respectively.

\section{Table 1}

Combinations in the context of land and building

\begin{tabular}{ccccc}
\hline Land & L-LPLQ & L-LPHQ & L-HPHQ & L-HPLQ \\
\hline Building & B-LPLQ & B-HPHQ & & \\
\hline
\end{tabular}

Using the four and the two combinations for the land and building respectively, a total of eight categories can be generated as follows:

(i) L-LPLQ-B-LPLQ

(ii) L-LPLQ-B-HPHQ

(iii) L-LPHQ-B-LPLQ

(iv) L-LPHQ-B-HPHQ

On the basis of the present discussion, the following propositions may be offered: (v) L-HPHQ-B-LPLQ

(vi) L-HPHQ-B-HPHQ

(vii) L-HPLQ-B-LPLQ

(viii) L-HPLQ-B-HPHQ

P1: In order to create a synergy between project and supply chain practices, the land and building characteristics play a significant role.

P2: Using price and quality factors, the land and building can be classified.

P3: The categorization of construction projects is significant on the basis of various combinations for land and building in the context of supply chain practices.

As it is discussed before, the supply chains compete usually on the price, quality, availability of the product, and lead time. The present categorization of the product on the basis of price and quality will be useful for the estimation of lead time and availability.

\section{Lead time and availability}

The present categories may also relate to the customer groups and an assessment of the requirement for each one will be helpful for project/ supply chain planning. For instance, in the category (i), i.e., LLPLQ-B-LPLQ, the quality requirements (in the context of facilities) are less specific. The risk (in the context of investment) of the builder is low because low costs are involved. Certain level of standardization may be planned. In some situations, the government also plans for such housing projects for lower income group people. The category (vi), i.e., L-HPHQ-B-HPHQ is at another extreme. The risks involved are high. Quality requirements are specific and may require a lot of 
negotiation/ interaction with the potential customers. As shown in Fig.3, the customer can approach through any channel.

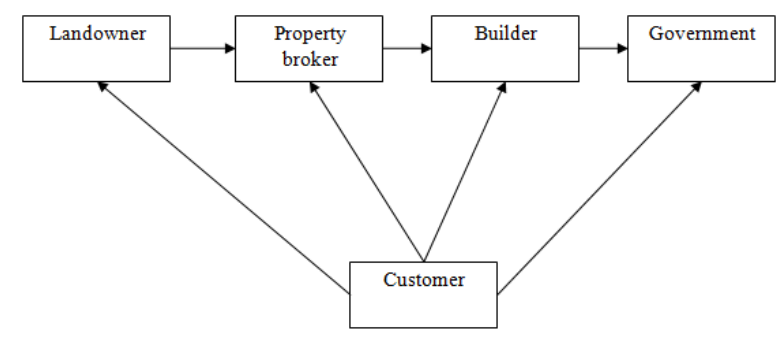

Fig. 3. Channel for the customer demand

The product may be available on demand, i.e., the availability is quite satisfactory from the customer point of view. On the other hand, the customer has to wait for the product after placing the demand. The lead time may refer to this elapsed time, i.e., between the time when the product was actually acquired and the time when the demand was raised. The discussed categorization is also helpful for determining:

(i) Whether it is justified to deliver the product on demand.

(ii) Whether certain lead time is necessary and agreed upon by all supply chain partners including the customers.

Fig.4 provides a guideline for an assessment of the lead time. However it should be analyzed location/ area wise.

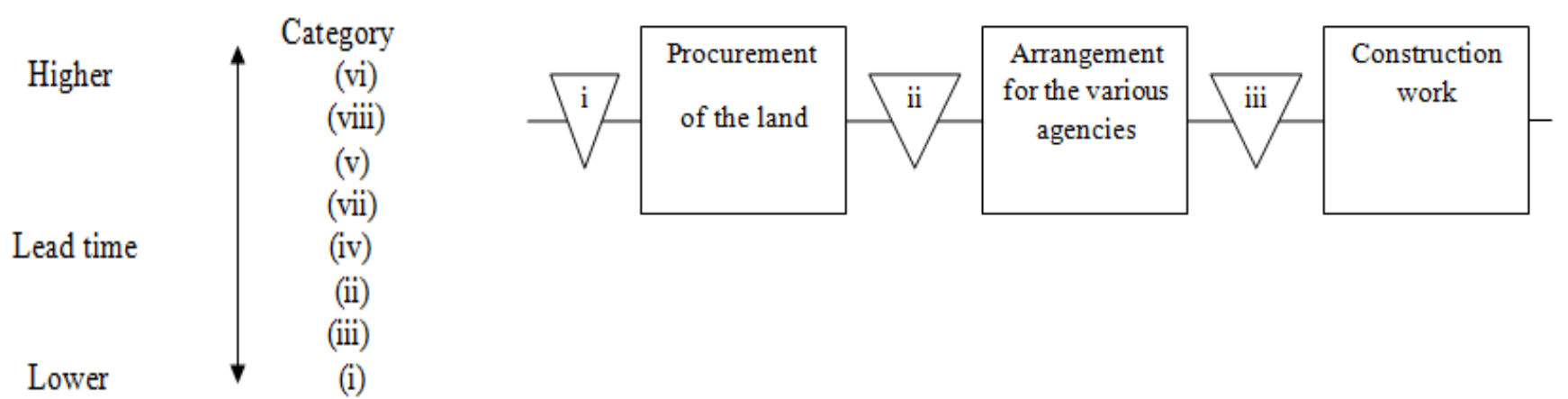

Fig.4. Guideline for the

Fig. 5. Positioning of the CODP

The lead time comprises of the two main activities:

(i) Procurement of the land

(ii) Completion of the building construction

Fig.4 is developed on the assumption that the B-HPHQ will take more time for completion as compared to the B-LPLQ, which may be generally true. In the context of the procurement of land, L-HPHQ may take more time as compared to L-LPLQ. Completion of the building construction may usually take more time as compared to the procurement of land; this is considered for an approximate determination of the intermediate positioning of the individual category. The supply chains have to decide about the Customer Order Decoupling Point (CODP). This may also refer to the stage from where the organization starts responding to the demand. For example, Fig.5 shows various positions of the CODP concerning few activities. If the company starts from the procurement procedure of the land after the arrival of demand, the position of CODP is at (i). In case where procurement of the land has been completed in anticipation of demand, the CODP is at a position (ii). Similarly it may also be at (iii) and so on. The lead time will decrease as the CODP shifts from left towards right side. Different categories 
have been discussed before. After an identification of the appropriate category, the corresponding CODP should be decided by the partners in the chain for a flawless execution of the projects. In the context of CODP determination, the following propositions may be offered:

P1: An estimation of the lead time and the availability is significant for the implementation of supply chain practices.

P2: The proposed categorization is useful for an estimation of the lead time.

P3: The developed categories are helpful for the determination of corresponding CODP.

\section{Reverse logistics}

In the previous sections, the general supply chain concepts have been mentioned in the specific context of construction management in order to introduce a synergy. There is an increasing trend of incorporating reverse logistics also in the supply chain scenario nowadays along with the forward logistics. Therefore this paper discusses briefly the reverse logistics also in the context of the construction products. For End Of Life (EOL) products, reverse logistics plays an important role. However the situation related to housing projects is different from the other general industrial products. Still certain conceptual understanding of the reverse logistics in the context of construction management would be useful in a synergistic environment wherever applicable. Different customers have different objective for the procurement of house such as:

(i) To use it as their own residence

(ii) To purchase for an investment purpose

(iii) Frequent buying and selling as their business.

As it is discussed before, the procurement of land is a significant activity in the construction management. Similarly people may have different objective concerning this, such as:

(i) Purchase the land and build own house for the residence

(ii) Purchase and sell to the construction companies/ individuals at an appropriate time

(iii) Long-term investment.

Table 2

Comparison of industrial and construction product

\begin{tabular}{|c|c|}
\hline Industrial product & truction product \\
\hline (i) Product is moving & (i) Product is stationary \\
\hline (ii) Tracking of the product for its whole life may be necessary & (ii) Tracking of the user for a long-term may be beneficial \\
\hline $\begin{array}{l}\text { (iii) Raw material and some components } \\
\text { may be reused at the EOL }\end{array}$ & $\begin{array}{l}\text { (iii) At the EOL or demolition stage, the } \\
\text { reuse may be difficult to visualize }\end{array}$ \\
\hline $\begin{array}{l}\text { (iv) Depending on the location/ } \\
\text { customer behaviour, the product may also be scra }\end{array}$ & $\begin{array}{l}\text { (iv) During the long-life, there may be selling/ buying } \\
\text { ing its life }\end{array}$ \\
\hline
\end{tabular}

Reverse logistics has been discussed widely with respect to the general industrial products in the available literature. Therefore it would be relevant to compare this with the construction product. This is shown in Table 2 in the context of reverse logistics. It is expected to be useful for creating suitable focus in the construction chain. An analysis of the category wise behaviour would be useful for the application of reverse logistics. Depending on a particular category, the items (used in the final construction of the house/ building) may be reused/ resold/ scrapped. As the conventional supply chain may focus on the reverse logistics also along with the forward one, the collection strategies may be developed in the present context. A proper tracking of the user/ product is advantageous for an implementation up to certain extent. In the supply chain scenario, a consolidation of the actual/ expected demand for items may be practiced. After making a forecast for each category, the common items/ modules can be identified and these can be consolidated for procurement/ storage planning. This will also be helpful for the cases like renovation or demolition at the end of life period for a product. 


\section{Concluding remarks}

The present paper has focused on the synergistic nature of the construction management and supply chain management. The unique contribution of this paper is the development of the categorization of construction product. This is done on the basis of land and building characteristics. Various combinations are expected to be useful for CODP determination and the forward/ reverse logistics implementation in this area. Lead time and availability estimation are important managerial activity for future planning and decisions. These will be facilitated with the help of present discussion. The future work may incorporate this conceptual development into more complex modeling, analysis, and case study approach.

\section{References}

Ahola, T., Laitinen, E., Kujala, J., \& Wikstrom, K. (2008). Purchasing strategies and value creation in industrial turnkey projects. International Journal of Project Management, 26(1), 87-94.

Aritua B., Smith, N.J., \& Bower, D. (2009). Construction client multi-projects - A complex adaptive systems perspective. International Journal of Project Management, 27(1), $72-79$.

Blackburn, J.D., Guide, V.D.R., Souza, G.C., \& VanWassenhove, L.N. (2004). Reverse supply chains for commercial returns. California Management Review, 46(2), 6-22.

Briscoe, G., Dainty, A.R.J., \& Millett, S. (2001). Construction supply chain partnerships: skills, knowledge and attitudinal requirements. European Journal of Purchasing \& Supply Management, 7(4), 243-255.

Chinyio, E.A., Olomolaiye, P.O., \& Corbett, P. (1998). An evaluation of the projects needs of UK building clients. International Journal of Project Management, 16(6), 385-391.

Christopher, M., \& Lee, H. (2004). Mitigating supply chain risk through improved confidence. International Journal of Physical Distribution and Logistics Management, 34(5), 388-396.

Christopher, M.G., \& Towill, D.R. (2002). An integrated model for the design of agile supply chains. International Journal of Physical Distribution and Logistics Management, 31(4), 262-264.

Edum-Fotwe, F.T., Thorpe A., \& McCaffer (2001). Information procurement practices of key actors in construction supply chains. European Journal of Purchasing \& Supply Management, 7(3), 155-164.

Fixson, S.K. (2005). Product architecture assessment: a tool to link product, process, and supply chain design decisions. Journal of Operations Management, 23(3-4), 345-369.

Germain, R., Claycomb, C., \& Droge, C. (2008). Supply chain variability, organizational structure, and performance: The moderating effect of demand unpredictability. Journal of Operations Management, 26(5), 557-570.

Giunipero, L.C., \& Pearcy, D.H. (2000). World class purchasing skills: an empirical investigation. Journal of Supply Chain Management, 36(4), 4-13.

Giunipero, L.C., \& Eltantawy, R.A. (2004). Securing the upstream supply chain: a risk management approach. International Journal of Physical Distribution and Logistics Management, 34(9), 698-713.

Hanafi, J., Kara, S., \& Kaebernick, H. (2008). Reverse logistics strategies for end-of-life products. International Journal of Logistics Management, 19(3), 367-388.

Hendry, J. (1995). Culture, community and networks: the hidden cost of outsourcing. European Management Journal, 13(2), 193-200.

Morris, P.W.G., Jamieson, A., \& Shepherd, M.M. (2006). Research updating the APM body of knowledge $4^{\text {th }}$ edition. International Journal of Project Management, 24(6), 461-473.

Pellegrinelli, S. (2002). Shaping context: The role and challenge for programmes. International Journal of Project Management, 20(3), 229-233.

Wikner, J., \& Rudberg, M. (2005a). Introducing a customer order decoupling zone in logistics decisionmaking. International Journal of Logistics - Research and Applications, 8(3), 211-224.

Wikner, J., \& Rudberg, M. (2005b). Integrating production and engineering perspectives on the customer order decoupling point. International Journal of Operations and Production Management, 25(7), 623641.

Wikner, J., \& Tang, O. (2008). A structural framework for closed-loop supply chains. International Journal of Logistics Management, 19(3), 344-366. 